\title{
Investigation of Mechanical Properties of Microalloyed Steels Joined by GMAW and Electrical Arc Welding
}

\author{
M. EKICI ${ }^{a}$ AND U. OZSARAC ${ }^{b, *}$ \\ ${ }^{a}$ Yalova University, Vocational School of Yalova, Yalova, Turkey \\ ${ }^{b}$ Sakarya University, Faculty of Technology, Department of Metallurgical and Materials Engineering \\ Esentepe Campus, Sakarya, Turkey
}

In this study, micro-alloyed steel samples were exposed to gas metal arc welding process by two welding wires coded ER100 SG and SG 3. Protection gases compositions were selected as $100 \%$ argon (Ar), $15 \% \mathrm{CO}_{2}+85 \%$ argon (MIG/MAG-1) and $25 \% \mathrm{CO}_{2}+75 \%$ argon (MIG/MAG-2) in three different types in order to investigate the $\mathrm{CO}_{2}$ effect on mechanical properties. In addition, an electric arc welding electrode coded Fox EV 85 was selected for arc welding applications to research the effect of welding method in mechanical properties. Welded joint were prepared at $130 \mathrm{~A}, 20 \mathrm{~V} ; 150 \mathrm{~A}, 22 \mathrm{~V}$ and $170 \mathrm{~A}, 24 \mathrm{~V}$ welding parameters. All welded joint specimens were exposed to tensile tests, Charpy impact tests to evaluate the yields strength, maximum tensile stress, fracture stress, \% elongation values and ductile-to-brittle transition temperatures values. Micro and macrostructure photos and scanning electron microscopy micrographs of specimens were obtained. The optimum parameters were advised to users at the end of this study.

DOI: 10.12693/APhysPolA.123.289

PACS: $81.20 . \mathrm{Vj}, 81.70 . \mathrm{Bt}, 81.05 .-\mathrm{t}, 81.05 . \mathrm{Bx}$

\section{Introduction}

Microalloyed steel is a type of alloy steel that contains small amounts of alloying elements (0.05 to $0.15 \mathrm{wt} \%$ ). Standard alloying elements include: niobium, vanadium, titanium, molybdenum, zirconium, boron, and rare-earth metals. They are used to refine the grain microstructure and/or facilitate precipitation hardening [1, 2]. These steels performance and cost land between carbon steel and low alloy steel. Yield strength is between 500 and $750 \mathrm{MPa}$ without heat treatment. Weldability is good, and can even be improved by reducing carbon content while maintaining strength. Fatigue life and wear resistance are superior to similar heat treated steels. The disadvantages are that ductility and toughness are not as good as quenched and tempered steels. They must also be heated hot enough for the all of the alloys to be in solution; after forming the material must be quickly cooled to 540 to $600{ }^{\circ} \mathrm{C}$ [1-3]. Cold worked microalloyed steels do not require as much cold working to achieve the same strength as other carbon steel; this also leads to greater ductility. Hot worked microalloyed steels can be used from the air cooled state. If controlled cooling is used, the material can produce mechanical properties similar to quench and tempered steels. Machinability is better than quench and tempered steels because of their more uniform hardness and their ferrite-pearlite microstructure [2, 4]. Because microalloyed steels are not quenched and tempered, they are not susceptible to neither quench cracking, nor do they need to be straightened or stress relieved. However, because of this they are thor-

*corresponding author; e-mail: ozsarac@sakarya.edu.tr oughly hardened and do not have a softer and tougher core like quench and tempered steels [2-6]. In present study, micro-alloyed steels were tried to join by two different welding methods namely gas metal arc welding (GMAW) and the electric arc welding by using different filler materials, and the mechanical properties of butt welded specimens were measured by destructive tests.

\section{Experimental studies}

Micro-alloyed steel was selected as base metal at the beginning of this study, because micro-alloyed steels have good welding ability and are commonly used in industry. Two types of welding methods were applied in order to compare the efficiencies of welding operations. GMAW was the first method and three different gas compositions were used here as $100 \% \mathrm{Ar}$ (MIG), $15 \% \mathrm{CO}_{2}+85 \% \mathrm{Ar}$ (MAG-1) and $25 \% \mathrm{CO}_{2}+75 \% \mathrm{Ar}$ (MAG-2). Two different filler wires coded as ER 100 SG and SG3 (G4Si1) were used in order to prepare specimens in butt weld position. The electric arc welding operations were performed by using a basic electrode coded as FOX EV 85 in three different welding current-voltage combinations as $130 \mathrm{~A}, 20 \mathrm{~V} ; 150 \mathrm{~A}, 22 \mathrm{~V}$, and $170 \mathrm{~A}, 24 \mathrm{~V}$. The chemical composition of base metal micro-alloyed steel and all filler materials used in experiments were given in Table.

The chemical compositions of base metal

TABLE and filler materials used in experiments (wt\%).

\begin{tabular}{c|c|c|c|c|c|c}
\hline \hline Materials & $\mathrm{C}$ & $\mathrm{Si}$ & $\mathrm{Mn}$ & $\mathrm{Mo}$ & $\mathrm{Ni}$ & $\mathrm{V}$ \\
\hline base metal & 0.032 & 0.212 & 1.386 & 0.043 & 0.094 & 0.012 \\
ER 100 SG & 0.08 & 0.44 & 1.70 & 0.30 & 1.35 & 0.08 \\
G4 Si1 (SG3) & 0.10 & 1.00 & 1.75 & & & \\
FOX EV 85 & 0.05 & 0.40 & 1.50 & 0.50 & 2.0 &
\end{tabular}




\section{Results and discussion}

GMAW and electric arc welding were applied to microalloyed steel and butt welded specimens were exposed to uniaxial tensile testing to measure the yield strength, ultimate tensile strength $\left(\sigma_{\mathrm{UTS}}\right)$ and fracture stress. The obtained results were shown in Fig. 1. GMAW values are higher than that of arc welding ones. MAG-1 group specimens have the highest strength values, but of course these values are also lower than that of base metal's which was not exposed to welding.

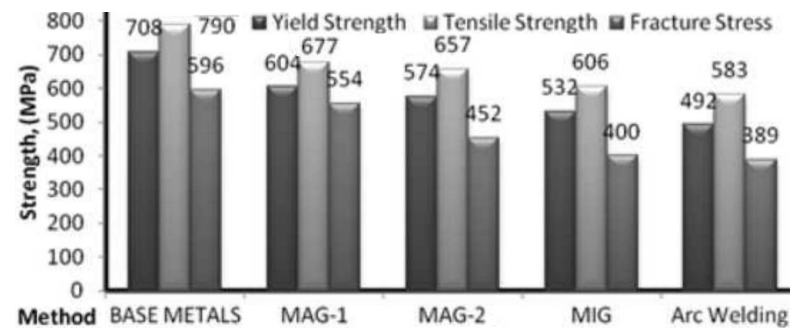

Fig. 1. Tensile test results of all specimens.

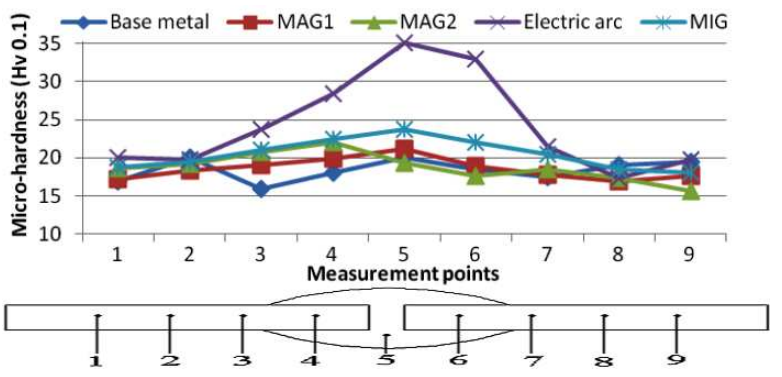

Fig. 2. Micro-hardness measurement points and values.

The micro-hardness values of butt welded specimens were measured from nine different points along the all specimens in $100 \mathrm{~g}$ load with $0.5 \mathrm{~mm}$ spacing. The mean values of two measurements in all group specimens were shown in Fig. 2. The highest hardness values were gained in electric arc welded specimens and micro-hardness values of MAG-1 group specimens have the lowest values. The hardness increases from base metal to heat affected zone (HAZ) and reaches the maximum values in weld zone. This tendency was seen in all specimens.

Micro-structures of all specimens were detected with optical microscope and scanning electron microscopy (SEM) and given in Fig. 3 and Fig. 4, respectively.

\section{Conclusion}

It was concluded from this study that MAG-1 gas composition with $15 \% \mathrm{CO}_{2}+85 \%$ Ar by means of ER $100 \mathrm{SG}$ filler wire must be selected in order to obtain the highest strength and optimum hardness and ductility values in joining of micro-alloyed steels. Electric arc welding method should not be preferred, because welding faults like gas hole and slag formation can occur as seen in SEM photos and lower strength values were obtained.

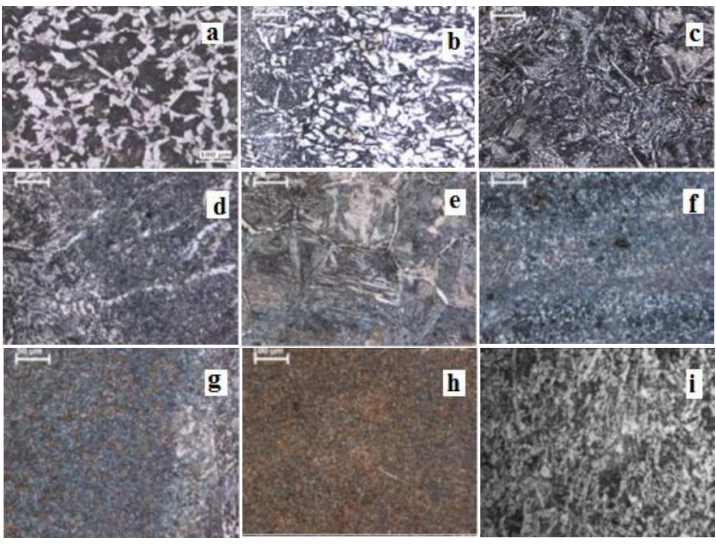

Fig. 3. Microstructures of (a) base metal, (b) HAZ/ weld zone of MAG-1, (c) HAZ of MAG-1, (d) base metal/HAZ interface in MAG-2, (e) base metal, (f) base metal/HAZ interface in electric arc welded specimens, (g) HAZ/weld interface in electric arc welded specimens, (h) weld zone in electric arc welded specimens, (i) weld zone in MAG-2.

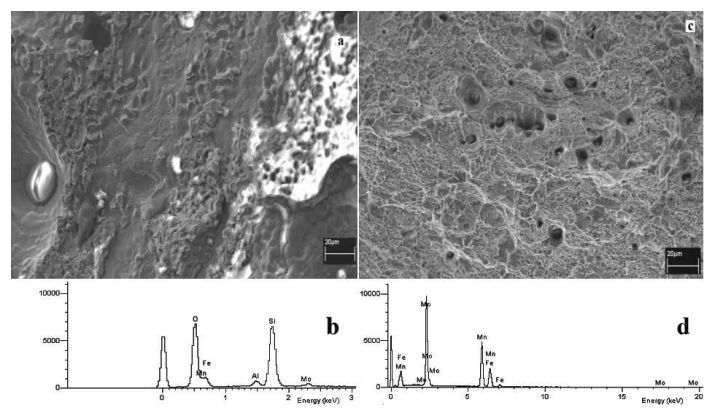

Fig. 4. SEM micrograph of (a) MAG-2 specimen welded by SG3 wire, and (b) its EDS analysis taken from white regions. Si-rich, oxidized regions were detected. (c) Fracture surface of electric arc welded samples joined by FOX EV 85 electrode. Black holes decreased the strength of weldments and low tensile test results were obtained with respect to GMAW specimens.

(d) Its EDS analysis showing Mo-rich regions.

\section{References}

[1] W.D. Callister, Materials Science and Engineering, 2nd ed., Wiley, Utah 1991.

[2] E.P. Degarmo, J.T. Black, R.A. Kohser, Materials and Processes in Manufacturing, 9th ed., Wiley, New York 2004.

[3] S.P. Chaudhuri, R.K. Mahanti, C.S. Sivaramakrishnan, M.P. Singh, Mater. Des. 23, 489 (2002).

[4] M.Y. Delince, E.D. Embury, M.D. Geers, P.J. Jacques, T. Pardoen, Acta Mater. 7, 2337 (2007)

[5] M. Ekici, M.Sc. Thesis, Sakarya University, Sakarya, Turkey 2009.

[6] E. Karadeniz, C. Yildiz, U. Ozsarac, Mater. Des. 28, 649 (2007) 